DEPARTMENT OF ECONOMICS

\title{
Estimating the direct costs of social conflicts: road blockings in Bolivia
}

Bruno De Borger \& Vincenzo Verardi

\author{
UNI VERSI TY OF ANTWERP \\ Faculty of Applied Economics \\ Stadscampus \\ Prinsstraat 13, B.213 \\ BE-2000 Antwerpen \\ Tel. +32 (0)32204032 \\ Fax +32 (0)3 2204799 \\ http://www.ua.ac. be/tew
}




\title{
FACULTY OF APPLIED ECONOMI CS
}

\author{
DEPARTMENT OF ECONOMICS \\ Estimating the direct costs of social conflicts: \\ road blockings in Bolivia \\ Bruno De Borger \& Vincenzo Verardi \\ RESEARCH PAPER 2008-013 \\ JUNE 2008
}
University of Antwerp, City Campus, Prinsstraat 13, B-2000 Antwerp, Belgium Research Administration - room B.213 phone: (32) 32204032
fax: (32) 32204799
e-mail: joeri.nys@ua.ac.be

The papers can be also found at our website:

www.ua.ac.be/ tew

( research $>$ working papers)

D/ 2008/1169/013 


\title{
Estimating the direct costs of social conflicts: road blockings in Bolivia ${ }^{1}$
}

by

\author{
Bruno De Borger and Vincenzo Verardi
}

\begin{abstract}
Social conflicts are a serious obstacle to economic growth in many Latin American societies, affecting economic activity both in the short- and the long-run. The purpose of this paper is twofold. First, we develop a methodology to estimate the direct, short-run impact of frequently occurring exponents of local conflicts (such as road blockings) on economic activity. The methodology is based on using high frequency (daily) data to estimate the relation between a proxy for economic activity and a proxy for local social conflicts. Careful analysis of impulse-response functions traces the effect of local social conflicts on economic activity. This information is combined with the aggregate annual time series relation between GDP and the high frequency proxy for economic activity to estimate the direct cost of local social conflicts for the economy as a whole. Second, we apply the proposed methodology to analyze the direct economic costs of road blockings in Bolivia, using detailed daily information for the year 2003. The results show that the direct costs of road blocking are large. Stronger institutions are a critical factor in reducing the prevalence of such conflicts and to avoid the huge economic costs that they imply.
\end{abstract}

Keywords: social conflicts, road blockings, impulse-response functions.

${ }^{1}$ De Borger: University of Antwerp, Belgium; Verardi: FUNDP, University of Namur and ULB, Brussels, Belgium.The authors would like to thank Marcelo Olivera for providing the data and for his input in the analysis. 


\section{Introduction}

It is well known that the determinants of economic growth in developing countries are complex and multi-dimensional; they include economic, political and institutional factors (see, among many others, Alesina and Rodrik (1994), Easterly, Kremer, Pritchett and Summers (1993), Knack and Kiefer (1995), Mauro (1995) and Platteau (2000)). Recently, the specific role of social conflicts in accounting for slow economic growth has been emphasized. For example, Rodrik (1999) forcefully argues that expressions of social instability hamper economic growth, both in the short and in the long run. In the short run, there is a direct reduction in economic performance, as effort is shifted away from productive activities. In the long-run, additional damage to the economy results, not only because conflicts raise uncertainty and hence reduce investment, but also because they typically postpone macroeconomic adjustments that may be badly needed. There is no doubt that social conflicts have played a major role in slow economic growth in many African and in some Latin American countries.

This paper deals with the short-run or direct implications of social conflicts for economic performance. More specifically, the purpose of the paper is twofold. First, we propose and develop a methodology to estimate the direct effects of recurrent expressions of local social conflicts, such as road blockings, for economic activity. The methodology combines annual time series data on economic activity with high frequency (daily) information on the occurrence of local social conflicts and proxies for economic activity. Careful analysis of impulse-response functions traces the effect of local social conflicts on economic activity. This information is combined with the aggregate annual time series relation between GDP and the high frequency proxy for economic activity to estimate the direct cost of local social conflicts for the economy as a whole. Second, we apply the proposed methodology to analyze the direct economic costs of road blockings in Bolivia, using detailed daily information for the year 2003; for reasons to be detailed below, we use information on the demand for hotel accommodation to proxy economic activity. Estimates of the effects of road blockings on the basis of the daily data are used to estimate the direct economic cost of this phenomenon at the aggregate level for the Bolivian economy. The results show that these costs are large. Obviously, since these estimates do not yet include the costs of long-run macroeconomic mismanagement and underinvestment, they have to be considered a lower bound of the overall costs of social instability. 
Applying the methodology to the problem of road blockings in Bolivia has a number of advantages. First, Bolivia is a Latin American country with rather poor economic performance; factors that contribute to this phenomenon include deeprooted social and ethnic conflicts, a lack of political institutions to manage such conflicts, poor infrastructure and a lack of access to the sea (Rodrik (1999), Faye, McArthur, Sachs and Snow (2004)). Second, Bolivia is characterized by an extremely high prevalence of social conflicts and is, in this unfortunate sense, an excellent candidate for applying the methodology we propose. Powerful social sectors (including unions) and weak political institutions imply that threats of conflicts are almost always credible. In 2003, expressions of civil unrest amounted to an astonishing 3896 incidents, of which 2371 were demonstrations and 944 strikes; there were 581 major road blockings. Third, the geographical situation of Bolivia implies that road blockings are indeed a direct threat to the economy, given the poor quality of other transport infrastructure and the lack of decent alternative roads. It is fair to say that blocking the corridor La Paz-Cochabamba-Santa Cruz paralyzes the economy. In 2003, the section La Paz-Cochabamba was blocked for 72 days, the section between Cochabamba and Santa Cruz for 47 days.

Structure of the paper is as follows. In Section 2 we provide some background on the role of social conflicts in explaining economic growth, with special emphasis on the Bolivian case. We then, in Section 3, describe the methodology we use to estimate the direct economic costs of road blocking on economic activity. Empirical implementation and results are presented in Section 4. A final section summarizes some policy conclusions.

\section{Social conflicts and economic growth}

In this section, we present a summary of recent empirical evidence on the role of social conflict in explaining differences in economic growth between countries, and then point at some extra complications implied by recent Bolivian history.

\subsection{The role of social stability in explaining economic growth}

The importance of social stability on economic growth has been stressed forcefully in a recent paper by Rodrik (1999). The argument is simple and economically appealing. Suppose that social divisions between different groups in a 
country are very deep due to, e.g., ethnic diversity and unequal political participation, and let the established institutions to prevent and to deal with potential conflicts be weak. Then consider an external shock to the economy in the form of, for example, deteriorating terms of trade that strongly reduce export possibilities. The reduction in economic activity that follows will then potentially lead to severe social conflicts between the different socially divided groups, because of coordination failures. If the various ethnic and social groups do not cooperate over reductions in overall economic activity, then negative external shocks imply that total demand will exceed available resources. This triggers distributive conflicts over the division of the reduction in the available pie between the different groups. Rodrik (1999) argues that the probability that different social groups disagree over who should bear what share of the burden of the declining economic activity is likely to be higher (i) in polarized societies, where latent social conflict is high; (ii) in societies where the return to unilateral action by one group is high; (iii) in societies where it is easy to exclude some groups from the pie, e.g., because the underdeveloped legal system does not prevent exclusion of minorities and those not politically represented.

Empirical regularities in the data on economic growth between countries and over time largely confirm the above ideas. The data show that it is not the occurrence of wars and the severity of economic external shocks themselves that matter for economic growth, but the different response to these shocks. For example, although in the period 1960-1973 economic performance in Latin-America was actually slightly better than in East Asia, social conflicts and the lack of strong institutions implied that productivity growth collapsed after 73 in the former region, but not in the latter. More specifically, the general finding in this literature is that external shocks have larger negative growth effects the larger the latent social conflicts (reflected in pre-existing social differences in wealth, ethnicity, regions, etc.) and the weaker the institutions to deal with emerging conflicts. Empirical tests use indices of ethno-linguistic fragmentation (such as the probability that 2 randomly drawn persons do not belong to same group), the Gini-coefficient of income inequality, the fraction of the population that does not speak the country's official language at home, indices of racial tension, the murder rate, a thrust index, etc. as proxy variables for social conflict. To capture the quality of institutions and of the government's conflict management abilities, proxies are constructed that reflect the existence of a rigorous framework of accepted rules and procedures that prevent hostilities and open conflicts 
(e.g., is there an independent judicial system, a non-corrupt bureaucracy, institutionalized social insurance, etc?).

The empirical evidence suggests that social conflict is the most important explanatory factor in explaining growth differences between countries. Pure economic policies (trade policies, debt-export ratios, government expenditure, etc.) at the outset of the crisis period have almost no extra explanatory power. As explained before, conflicts immediately disrupt economic activity; in the medium and long run, they delay policy adjustments that are badly needed, they imply economic uncertainty and hence lower investment, and they focus effort on distributive issues rather than productive ones.

\subsection{Social polarization, trust and economic performance}

The role of social polarization in explaining economic performance has recently also been emphasized from a different perspective. Knack and Keefer (1997) stress the role of trust and civic cooperation within a society. This is found to be more important in explaining economic performance than horizontal social capital reflected by, e.g., active participation of the population in social organisations ${ }^{2}$. Importantly, the authors show that low social polarization and the existence of formal institutional rules that restrict arbitrary government decisions are the main contributing factors to trust and civic cooperation. In countries such as Bolivia, where due to high social polarization trust is low, institutional reforms that allow the enforcement of contracts and that facilitate access to credit are found to be crucial: in a sense, they substitute for the absence of trust.

\subsection{Social instability, access to the sea, and economic performance in Bolivia}

Note that the determinants of social instability described before (strong ethnolinguistic fragmentation, high income inequality, a large fraction of the population that does not speak the country's official language, lack of thrust, etc.) almost all apply strongly to Bolivia; in this sense, intensive social conflicts due to ethnic, professional and income divisions are not surprising. Moreover, the lack of a rigorous legal framework of accepted rules and procedures that prevent hostilities or exponents of conflicts (such as road blockings) imply frequent occurrence of such phenomena.

\footnotetext{
${ }^{2}$ Interestingly, group membership is found to be unrelated to performance; it is also unrelated to the development of trust.
} 
Apart from the above very unfavourable conditions for economic growth, Bolivia's particular geographical location and the international tensions with several of its neighbours, have contributed to poor economic performance. One determinant of economic growth which dominates Bolivian history, and has only very recently received some widespread empirical support, is the role of access to the sea. Apart from the obvious distance to the sea, at least four reasons for the relatively poor performance of landlocked countries have been identified (see Faye, McArthur, Sachs and Snow (2004)): (i) the dependency on the quality of the neighbours' infrastructure, needed to access the sea; (ii) the importance of sound cross-border political relations, (iii) the importance of neighbours' peace and stability, and (iv) the quality of neighbours' administrative practices. Using a large dataset, Faye et al (2004) show that landlocked countries have lower GDP per capita, they face higher transport costs of trade (transport cost plus insurance relative to value of exports), and they have lower exports compared to otherwise comparable nations that have access to the sea.

It is hard to judge the importance of the above argument for the poor economic growth in Bolivia. It is obvious that the lack of access to the sea, and the resulting tensions and poor international relations with Chile (e.g., the war 1878-1883) have affected economic growth (for example, they recently lead to a delay in the export of gas). On the other hand, however, the infrastructure of Bolivia's neighbours is generally of decent quality, and the administrative and physical borders with Brazil, Argentina, Peru and Chile have almost never been closed. The main infrastructural problem seems to be situated in Bolivia itself: domestic corridors are poorly maintained so that the decent infrastructure in neighbouring countries is insufficient to stimulate economic growth. In this sense, good prospects should exist because natural gas reserves do not require rail or road connections. In sum, however, there is no doubt that being landlocked has strong disadvantages for economic growth, but it is equally clear that in Bolivia the issue of lost access to the sea is as much a cause of social unrest as it is an impediment to growth.

\subsection{Limiting the incidence of social conflicts: the decentralisation process in Bolivia}

Reducing the incidence of social conflicts and creating a better environment for economic growth was one of the main reasons for initiating the decentralisation process (Verardi (2003)). The idea was to increase the participation of the population in decision making processes, and at the same time making available additional funds 
at the local level to finance local public services. The process involved, among others (see, e.g., Faguet (2004)): (i) the creation of 198 new municipalities; (ii) the decentralisation of responsibilities for health, education, roads, and irrigation to the local level; (iii) the per capita allocation of $20 \%$ of national tax revenues to municipalities; and (iv) the installation of Local Oversight Committees to check spending of funds, and to propose new projects.

Economic theory has generated different views on the desirability of decentralisation, and the evidence is mixed ${ }^{3}$. The available Bolivian evidence suggests that the reform had a series of fairly positive implications (Faguet (2004)). It implied substantial redistribution of both power and financial resources to lower levels, investment in local services per capita went up, and services were better adapted to indicator variables expressing local needs. For example, it was found that educational expenditures shifted to areas with higher rates of illiteracy. At the same time, of course, the decentralization movement reduced the redistributive role of the national government (Verardi (2005), Bouton, Gassner and Verardi (2007)).

\section{Methodology}

Our purpose is to estimate the direct effect of road blockings on economic activity in Bolivia. As daily data are available on road blockings but standard indicators for economic activity, such as gross domestic product, are available only for highly aggregated periods of time, we exploit the high frequency nature of the data on social unrest by using a two step-procedure. We first look for an economically appealing and statistically convincing proxy for economic activity that has two properties: (i) it captures both the short- and the long-run dynamics of aggregate economic activity very well, i.e., it correlates almost perfectly with aggregate economic activity, and (ii) it is available both at the aggregate level and at the same high frequency level (i.e., daily information is available) as the road blocking data.

\footnotetext{
${ }^{3}$ One view is that it is a positive development (Zax (1989), Shah (1998)), because it makes governments more responsive to the preferences of local and, almost by implication, more homogenous groups. The opposite view argues, however, that the local government's lack of technical and human resources prevents it from providing decent services, and that power should remain with the better equipped higher level authority. In general, the available case studies are inconclusive, although there seems to be a slight advantage for the former view. For example, Huther and Shah (1998) find a positive relation between decentralisation and indicators of political participation, social development and quality of government.
} 
We then estimate the direct effect of road blockings on economic activity, using daily information on road blockings and the proxy variable identified at step one. The time series properties of this relation are exploited to derive information on the costs of road blockings.

\subsection{Identifying proxies for daily economic activity}

In a first step, we search for an economically sensible and statistically acceptable proxy for economic activity. Data availability limits the number of candidates. Fortunately, it is well known that in many countries a close correlation exists between the demand for hotel accommodation, on which data are available for the Cochabamba region both at the daily and the aggregate level, and economic activity (see, e.g., the USA Lodging industry sector reports). In the rest of this subsection we show, using straightforward statistical tests, that also for the Bolivian case activities in the hotel business correlate almost perfectly with economic activity in general, both in the short and the long-run.

In Figure 1, we show annual time series for the Gross Domestic Product (GDP) of the lodging industry and for total GDP in Bolivia. Correlation between the logs of these variables amounts to 0.985 . Of course, both series are highly trended; they were both found to be integrated of order 1. Engle-Granger tests rejected the hypothesis of no co-integration between the two series.

To improve the long-run relationship between the two variables while at the same time capturing the short-run dynamics, we estimated an error correction model, using Bolivian GDP as the dependent variable $y_{t}$. The following model is postulated:

$$
y_{t}=\beta_{1}+\beta_{2} y_{t-1}+\beta_{3} x_{t}+\beta_{4} x_{t-1}+\varepsilon_{t}
$$

To facilitate interpretation, note that this can be rewritten as:

$$
\Delta y_{t}=\left(\beta_{2}-1\right)\left(y_{t-1}-\frac{\beta_{1}}{1-\beta_{2}}-\frac{\beta_{3}+\beta_{4}}{1-\beta_{2}} x_{t-1}\right)+\beta_{3} \Delta x_{t}+\varepsilon_{t}
$$

The model implies that the change in GDP in any period is explained by the change in production of the hotel business and the deviation between lagged GDP and the value predicted by the long-run cointegrating relationship. Estimation results showed the significance of the coefficient of lagged hotel production levels $x_{t-1}\left(\beta_{4}=0.88\right)$; none of the other coefficients were significant. The results suggested that the short-term correction slightly improved the long-run relationship; most importantly, it shows that 
$x_{t-1}$ is a very good proxy for Bolivian GDP. The estimated correlation amounts to 99.57. We exploit the close correlation between the hotel business and GDP to estimate the direct impact of road blockings on economic activity further in this paper.

\subsection{Local economic activity, social unrest, and road blockings}

Previous aggregate relations are combined with daily information on expressions of social unrest in the form of road blockings and local hotel activity as proxy for economic activity. The data used are daily data for 2003 on the number of incoming visitors ${ }^{4}$ in Cochabamba hotels and detailed information on road blockings due to social upheaval on access roads to Cochabamba. The focus on Cochabamba seems acceptable for two reasons: first, the Cochabamba economy is a good barometer for the Bolivian economy (economic indicators correlate for 99.25); second, due to its central geographical position, Cochabamba is very well suited to test effects of road blockings, because it is always directly affected.

In Figure 2 we document incoming hotel visitors in Cochabamba over 2003 together with the main social conflicts in the course of this same year. Overall, there were 49 days of major conflict, divided into 4 groups of unrest, lasting 3, 5, 16 and 25 days, respectively. These included, among others, a global strike against neoliberalism in general and the proposal to export gas through Chile in particular, and a global strike against a new income tax proposal. Total indications of civil unrest were much larger, however, amounting to an astonishing 3896 'incidents'; these included 2371 demonstrations, 944 strikes and 581 major road blockings. As indicated above, our focus is on road blockings. They are an obvious threat to the economy, given the poor quality of infrastructure and the lack of decent alternative roads. For example, it is fair to say that blocking the corridor La Paz-Cochabamba-Santa Cruz paralizes the economy. In 2003, the road La Paz-Cochabamba was blocked 72 days, the road Cochabamba-Santa Cruz for 47 days.

\subsection{Estimating the effect of road blockings on economic activity: methodology}

The methodology we use is based on standard time series techniques applied to the 365 daily observations on incoming hotel visitors as proxy for economic activity, and daily information on road blockings on the access roads to Cochabamba.

\footnotetext{
${ }^{4}$ We consider the incoming visitors rather than the occupation rate to avoid keeping people that had to remain in hotels due to road blockings.
} 
First, we identify the underlying ARIMA process for the log(hotel incoming) series, taking into account that some pure exogenous shocks could affect the process (more specifically, we identify an ARIMAX procedure). More specifically, some dates such as the day of Cochabamba, the Urkupiña celebration and the international festivities (Easter, Carnival, first of May and All Saints) are typically associated with a large hotel inflow and have to be accounted for. We use the standard Box-Jenkins methodology to find the appropriate auto-regressive and moving average structure. ${ }^{5}$ It turns out that an ARMA $(1,7,1)$ was the most appropriate structure. On the basis of the estimated process we then analyzed impulse responses function according to four types of shocks (see, e.g., Enders, Sandler and Cauley (1990) for a similar approach to estimate the effects of terrorism attacks). We consider the effects of a one-day shock (think of a one-day road blocking), a series of recurrent shocks, a prolonged shock lasting for many days, and a series of prolonged shocks. Finally, the impulse response functions are analyzed, and the model is used to estimate the loss of economic activity due to road blockings.

\section{Empirical results}

We first present the estimated model. Then we use the model to analyze impulse response functions. Finally, we estimate the economic losses of road blockings.

\subsection{Time series results}

The results are presented in Table 1 . The dependent variable is the log of incoming hotel visitors. We use two different measures of the expression of social conflict. In the first column we consider the blocking of the new Santa CruzCochabamba road (basically the only good road connecting the major cities of Bolivia), while in the second we take a broader definition and consider all national strikes. The $\log$ (incoming hotel visitor)-series was found to be stationary ( $\mathrm{p}$-value=0, Augmented Dickey-Fuller unit-root test).

What do we learn from these estimates? First, the conflict coefficients indicate that hotel inflow went down by some $13-15 \%$ the day after a conflict. Note that this

\footnotetext{
${ }^{5}$ We considered that variance could be modelled as well but neither a GARCH nor a SARIMA structure seemed to improve the estimations.
} 
holds independently of the major upheaval in October; in fact, the dummy for October just indicates that October was even much worse. Second, note that the structure best describing the dynamic behaviour of the incoming hotel visits was an ARMA $(1,7,1)$ process. The auto-regressive coefficients L1 and L7 suggest that seven days after a conflict, its effect partially re-emerges. Third, all the other explanatory variables reflecting different types of festivities and cultural events have the expected sign; especially Easter generates large hotel inflows. Finally, note that the use of two widely different conflict measures does not lead to large differences in coefficient estimates. This may seem surprising. However, it just follows from the important role of the New Santa Cruz-Cochabamba road; its blocking is highly likely whenever a national issue is at stake. This can be explained by several factors. First, the Chapare region, that is crossed by the road, is the basis of MAS; second, the Santa Cruz region is the most productive region of the country, so that blocking links to the markets of Cochabamba is a highly effective instrument for exercising pressure.

\subsection{Analysis of impulse-response functions}

We use the estimated model to analyze the response of the system to four types of impulses. In Figure 3 we present impulse response functions that show the behaviour of the estimated dynamic system after one of four different types of shocks. The first one (Impulse), in the upper left corner, corresponds to a single day conflict. The second one (Prolonged impulse), in the upper right, corresponds to a week of conflicts. In the two last graphs (recurrent impulse and recurrent and prolonged impulse), we present respectively how the economy reacts to a series of three one-day shocks and a series of three one-week shocks.

To estimate the impulse response functions we started by setting the log (incoming visitors) variable to zero. Then, for the case of a single day impulse, in the second period we set the conflict variable equal to one. We thus observe the reduction induced by this crisis. Then we let the dynamic stochastic process run and estimate the incoming hotel variable to see how it behaves over time. ${ }^{6}$ A similar approach is adopted for the other scenarios. Note that these exercises do not necessarily produce perfectly realistic dynamics, in the sense that the shocks were exogenously applied and may not be consistent with what is observed. However, they do illustrate the

\footnotetext{
${ }^{6}$ For the MA component, we estimate the residuals and introduce them in the process.
} 
behaviour of the system, and they provide information on the lags involved in phasing out the effects of the shocks.

Consider the impulse response function of Figure 3. For a one-day conflict we see, consistent with the conflict coefficients estimated before, that economic activity drops instantaneously by $13 \%$. Importantly, more than a week is needed to phase out the effect of the shock and to return to the long-run process. A prolonged conflict of a week implies a drop in economic activity of almost $25 \%$, and almost a month is needed to go back to the long term path. A series of several one-day conflicts, and especially a series of several longer conflicts (probably the most realistic description of the Bolivian situation), implies a continuous reduction in activity, where the intensity of the loss rises again with each renewed negative impulse.

\subsection{The implied direct economic losses of social conflicts}

In view of the information of the impulse response functions one can expect the economic losses of road blockings, given their widespread and frequent occurrence, to be substantial. Estimating these losses on the basis of the estimated model is the purpose of the present subsection.

To estimate the loss induced by the actual conflict days in the year 2003, we applied the same methodology as before; so we set the process equal to zero and analyze the impulse function by setting the conflict variable equal to one at each day of social unrest. Unlike the exogenous shocks applied in the previous subsection, this does provide us with estimates of the implications of the observed road blockings in 2003, since the impulses are now describing what was exactly observed. The results are depicted in Figure 4.

The results show that the national conflict that dominated October had a huge cost in terms of lost economic activity: some $80 \%$ of activity was lost for more than half of October; towards the end of the month, the loss dropped to $60 \%$. It took the country well into November before economic activity resumed its normal pace. Apart from October, substantial economic losses were also estimated for the second half of January (up to more than 20\%), February and March (drop in activity by 20\% in the last week).

In a final step, we integrate the results over the whole year 2003, to obtain an estimate of the economic loss in activity (i.e., reduction in GDP) due to social unrest. The results suggest that the production loss is some $10 \%$ on average over the year. In 
some periods the loss is much more dramatic, of course. For example, as could be expected the loss in October amounts to almost 80\%. This figure should be cautiously interpreted. As argued before, since it only covers the direct short run impact and not the long run effects due to macroeconomic destabilisation, it is just a modest fraction of the total effect.

\section{Conclusions}

We have proposed and applied a methodology to estimate the direct effects of recurrent exponents of local social conflicts, such as road blockings, on economic activity. The methodology combines annual time series data on economic activity with high frequency (daily) information on the occurrence of local social conflicts and proxies for economic activity. We applied the proposed methodology to analyze the direct economic costs of road blockings in Bolivia, using detailed daily information on road blockings for the year 2003. The results show that these costs are large. The national conflict that dominated October implied that $80 \%$ of activity was lost for more than half a month. It took the country well into November before economic activity resumed its normal pace. Other substantial economic losses were estimated for the second half of January (up to more than 20\%), February and March (drop in activity by $20 \%$ in the last week).

Since these estimates do not yet include the costs of long-run macroeconomic mismanagement and underinvestment, they have to be considered an absolute lower bound for the overall costs of social instability. Stronger institutions are a critical factor in reducing the prevalence of such social conflicts and to avoid the huge economic costs that they imply.

\section{References}

Alesina, A. and D. Rodrik (1994), Distributive politics and economic growth, Quartely Journal of Economics 109, 465-490. 
Bouton, L, Gassner, M. and. V. Verardi (2007), Redistributing Income Under Fiscal Vertical Imbalance. LIS working paper series, n.420.

Easterly, W., Kremer, M., Pritchett, L. and L. Summers (1993),Good policy or good luck? Country growth performance and monetary shocks, Journal of Monetary Economics 32, 459-483

Enders, W., Sandler, T. and J. Cauley (1990). UN conventions, technology and retaliation in the fight against terrorism: an econometric evaluation. Terrorism and Political Violence 2, 83-105.

Faguet, J.-P. (2004), Does decentralisation increase government responsiveness to local needs? Evidence from Bolivia, Journal of Public Economics 88, 867-893.

Faye, M.L., McArthur, J.W., Sachs, J.W. and T. Snow (2004), The challenges facing landlocked developing countries, Journal of Human Development 5, 31-68.

Huther, J. and A. Shah (1998), Applying a simple measure of good governance to the debate on fiscal decentralization, World Bank, Policy Research paper 1894, Washington, D.C.

Knack, S. and P. Keefer (1995), Institutions and economic performance: cross country tests using alternative institutional measures, Economics and Politics VII, 207-227

Knack, S. and P. Keefer (1997), Does social capital have an economic payoff? A cross country comparison, Quarterly Journal of Economics, 1251-1288.

Mauro, P. (1995), Corruption and growth, Quarterly Journal of Economics, 681-712

Rodrik, D. (1999), Where did all the growth go? External shocks, social conflict, and growth collapses, Journal of Economic Growth 4, 385-412

Platteau, J.P. (2000), Institutions, social norms and economic development, Harwood Academic Publishers, London.

Shah, A. (1998), Balance, accountability and responsiveness: lessons about decentralization, World Bank, Policy Research paper 2021, Washington, D.C.

Verardi, V. (2003), Electoral Systems, Racial Tensions and Decentralization, Acta Nova, Vol. 2, No. 3, p. 367-386

Verardi, V. (2005), Electoral systems and income inequality, Economics Letters 86, 7-15.

Zax, J. (1989), Initiatives and government expenditures, Public Choice 63, 267-277. 
Table 1: The effects of social conflict on hotel inflows

\begin{tabular}{|c|c|c|}
\hline \multirow[b]{2}{*}{ Conflict (lagged) } & \multicolumn{2}{|c|}{ Log (Incoming) } \\
\hline & $\begin{array}{l}-0.145^{\star \star \star} \\
(2.93)\end{array}$ & $\begin{array}{l}-0.128^{\star \star} \\
(2.50)\end{array}$ \\
\hline October & $\begin{array}{l}-0.304^{\star \star \star} \\
(3.15)\end{array}$ & $\begin{array}{l}-0.308^{\star \star \star} \\
(3.18)\end{array}$ \\
\hline Urkupina & $\begin{array}{l}0.339 \\
(1.42)\end{array}$ & $\begin{array}{l}0.349 \\
(1.45)\end{array}$ \\
\hline Cochabamba & $\begin{array}{l}0.205 \\
(1.10)\end{array}$ & $\begin{array}{l}0.228 \\
(1.24)\end{array}$ \\
\hline Carnival & $\begin{array}{l}0.407^{\star \star \star} \\
(3.28)\end{array}$ & $\begin{array}{l}0.409^{\star \star \star} \\
(3.27)\end{array}$ \\
\hline Easter & $\begin{array}{l}0.514^{\star \star \star} \\
(5.34)\end{array}$ & $\begin{array}{l}0.517^{\star \star \star} \\
(5.32)\end{array}$ \\
\hline Ist May & $\begin{array}{l}0.385^{\star \star *} \\
(3.88)\end{array}$ & $\begin{array}{l}0.382^{* * *} \\
(3.83)\end{array}$ \\
\hline All Saints & $\begin{array}{l}0.247^{\star \star *} \\
(5.92)\end{array}$ & $\begin{array}{l}0.257^{\star \star \star} \\
(6.67)\end{array}$ \\
\hline Constant & $\begin{array}{l}6.014^{\star \star \star} \\
(263.29)\end{array}$ & $\begin{array}{l}6.013^{\star \star \star} \\
(255.61)\end{array}$ \\
\hline AR & & \\
\hline Lag 1 & $\begin{array}{l}0.450^{\star \star \star} \\
(5.00)\end{array}$ & $\begin{array}{l}0.466^{\star \star \star} \\
(5.35)\end{array}$ \\
\hline Lag 7 & $\begin{array}{l}0.133^{\star \star} \\
(2.51)\end{array}$ & $\begin{array}{l}0.135^{\star \star} \\
(2.55)\end{array}$ \\
\hline MA & & \\
\hline Lag 1 & $\begin{array}{l}0.183^{\star *} \\
(2.00)\end{array}$ & $\begin{array}{l}0.145 \\
(1.65)\end{array}$ \\
\hline OLS R ${ }^{2}$ & $59.41 \%$ & $58.54 \%$ \\
\hline Observations & 364 & 364 \\
\hline
\end{tabular}

Absolute t statistics in parentheses

${ }^{\star *}$ significant at $5 \%$; *** significant at $1 \%$ 
Figure 1: Incoming hotel flows and GDP

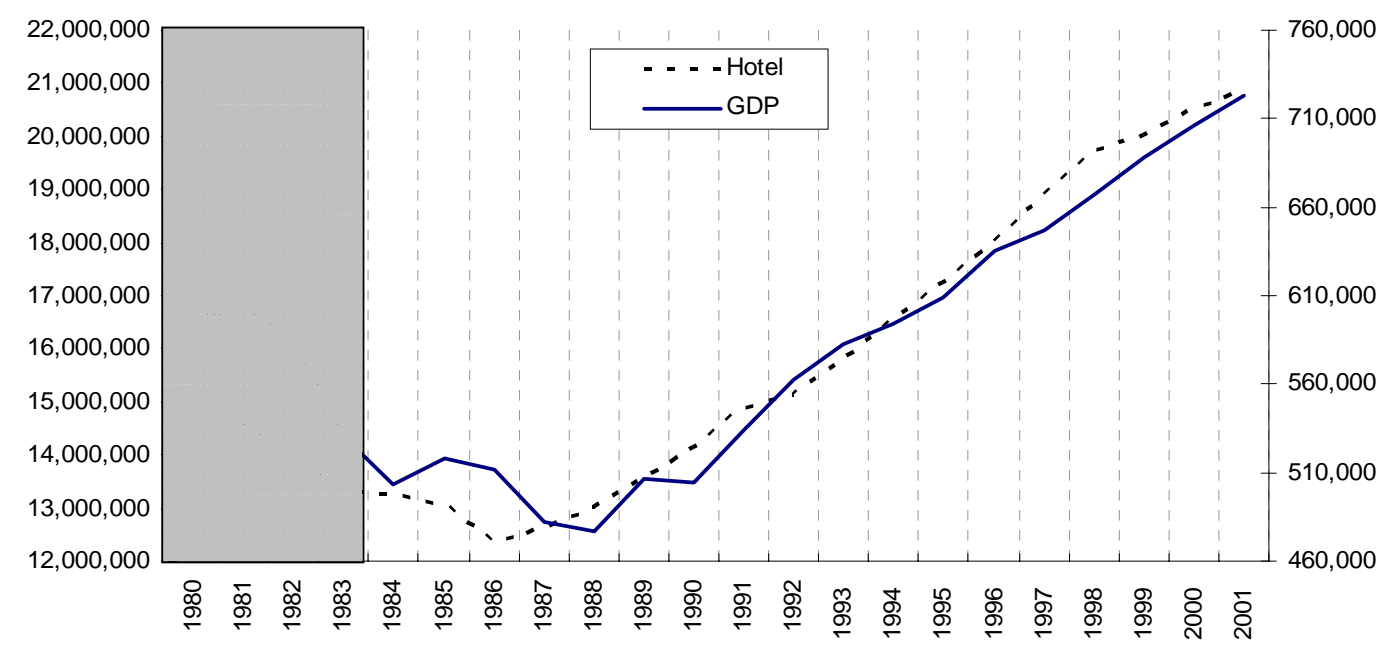

Figure 2: Incoming hotel flows and social conflicts

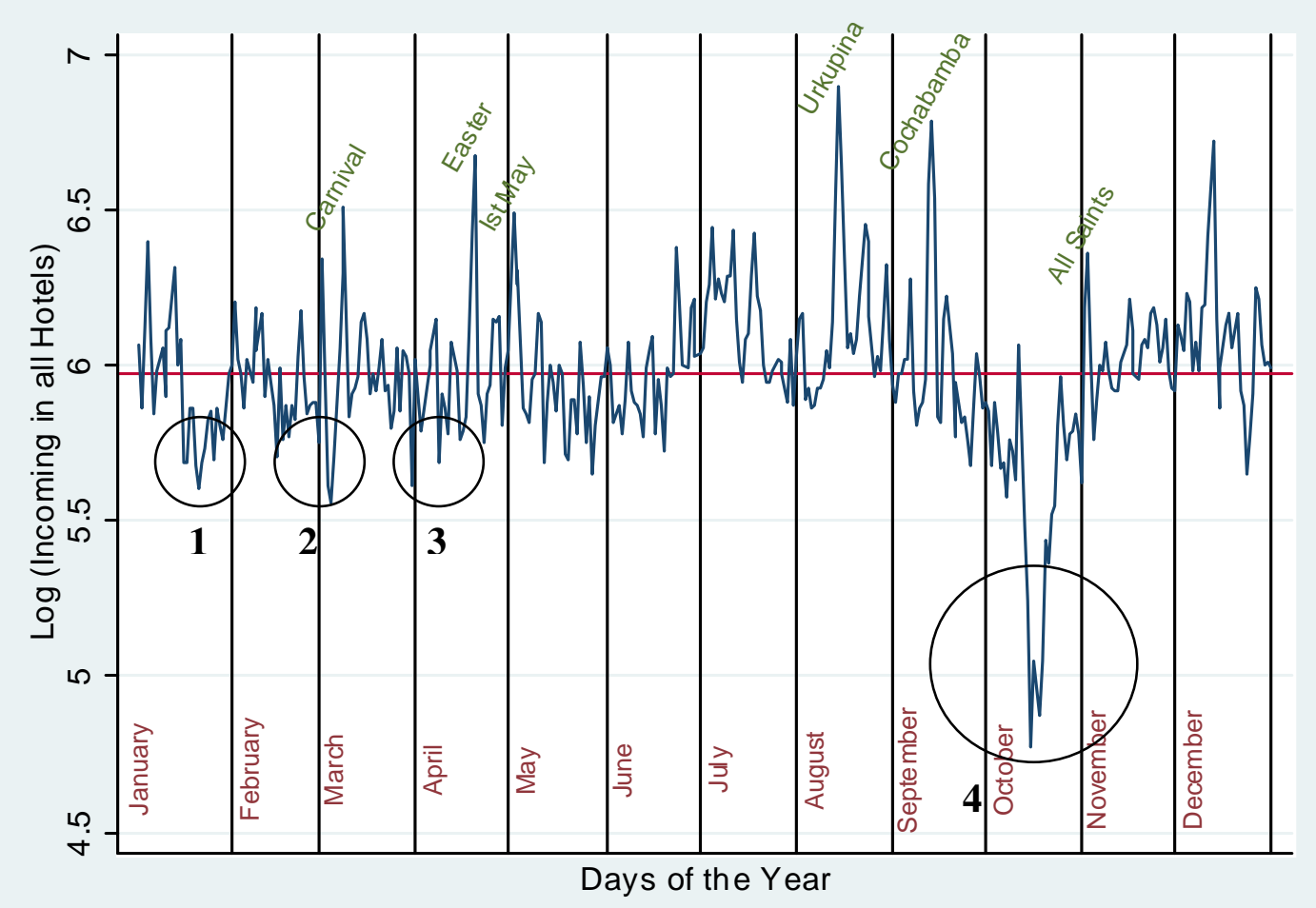


Figure 3: Simulated impulse response functions
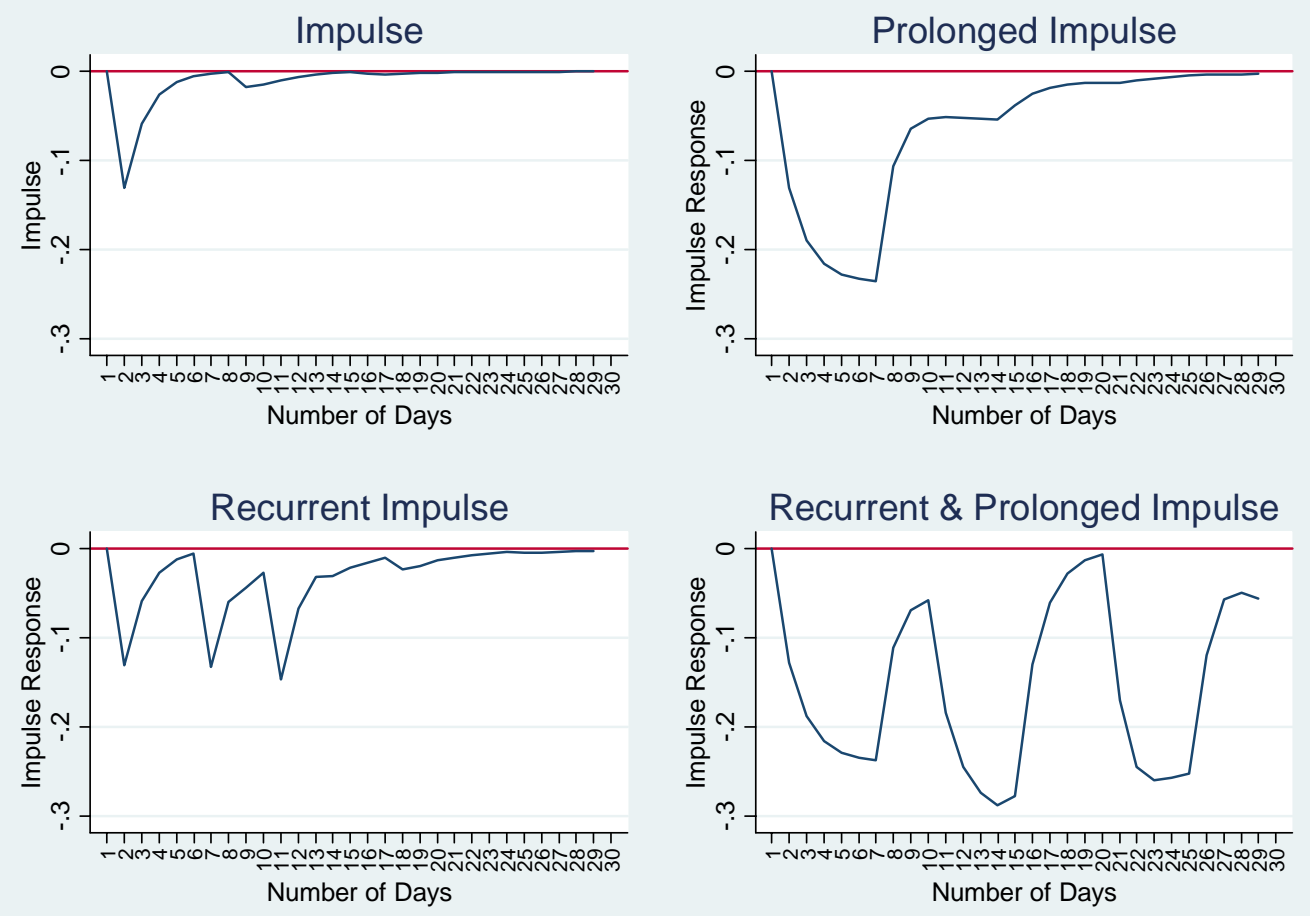

Figure 4: Social conflicts (impulse) and reduction in economic activity (response)

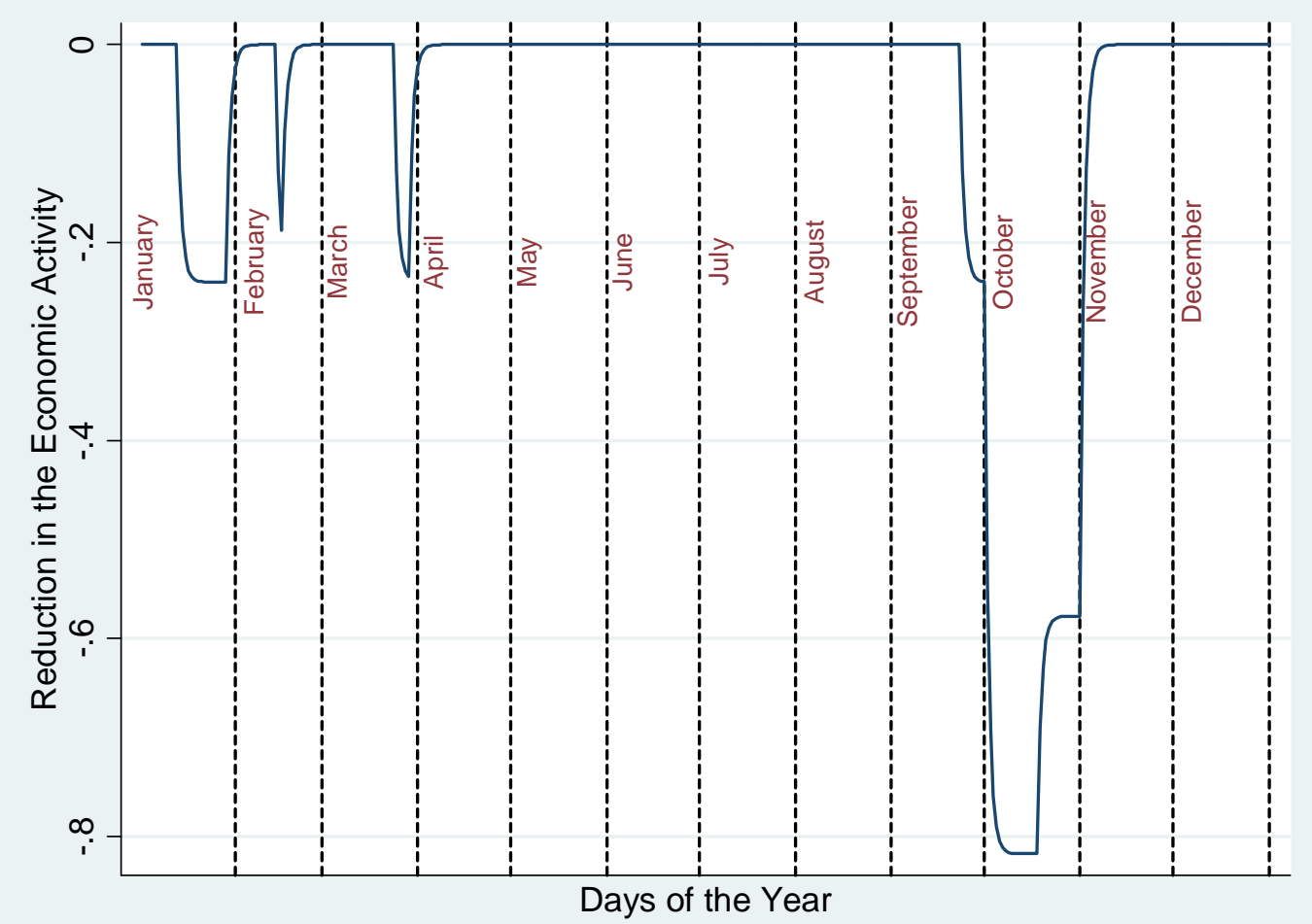

